\title{
Knowledge and Attitude of HIV Counselling and testing among Males aged 18-30 years in Kyeizooba Community, Bushenyi District.
}

\author{
Blutus Niwamanya $a^{a}, 1,2$ \\ a Department of Nursing, Mbarara University of Science and Technology
}

\begin{abstract}
\end{abstract}

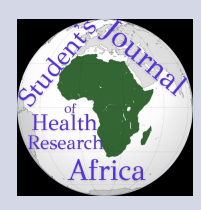

Background: ${ }^{a}$

In 2018, an estimated 1.4 million people were living with HIV, and an estimated 23,000 Ugandans died of AIDS-related illnesses. As of 2018, the estimated HIV prevalence among adults (aged 15 to 49 ) stood at $5.7 \%$. HIV testing is often used as an umbrella term to refer to both testing and counseling services. The use of HIV testing and counseling is closely related to education level, fear to disclose results, stigma, and discrimination towards HIV/AIDs patients. In the Kyeizooba sub-county, there is a low turn up for HCT services among males aged 18-30 years compared to females of the same age and the reasons behind the cause are missing.

Methods:

This was a cross-sectional study design that used, convenient sampling to get the needed participants. The sample size was determined by Kish \&Lesley (1965) method of sample estimation. All participants that met the inclusion criteria were 78. A self-administered questionnaire was used to collect the data and analyzed using SPSS 20.0. Permission was sought from the nursing department, faculty research committee from MUST, and further permission from DHO.

Results:

Most participants were married (37.2\%), secondary level (44.9\%), and unemployed youth (42.3\%). Most of the participants scored between 5-7 as moderate knowledge.

Most of the participants scored below 22.5 with an average score of 16.6 (negative attitude) others agreed with blood loss during testing, stress, stigma, and discrimination. Most had never tested $68 \%$, preferred health facility $48.7 \%$ as a testing site.

\section{Conclusion:}

Most of the participants had moderate knowledge which is attributed to education level and most had a negative attitude towards HCT.

\footnotetext{
${ }^{a}$ email: niwamanyablutus@gmail.com recieved: 29th/12/2020 accepted: 5 th/02/2021 journal of healthcare counselling.
}

\section{BACKGROUND}

Globally, HIV continues to be the greatest threat and mostly in developing countries claiming more than 32 million lives which is alarming However, with increasing access to effective HIV prevention, diagnosis, treatment, and care, HIV infection has become a manageable chronic health condition, enabling people living with HIV (PLWH) to live longer and healthy lives (World Health Organization, 2019). 
HIV can be transmitted via unprotected and close contact with a variety of body fluids of infected individuals, such as blood, breast milk, semen, and vaginal secretions and usually individuals cannot become infected through ordinary day-to-day contact such as kissing, hugging, shaking hands, or sharing personal objects, food, or water. (WHO, 2019).

As a result of concerted international efforts to respond to HIV, coverage of services has been steadily increasing and of $2018,62 \%$ of adults and $54 \%$ of children living with HIV in low- and middleincome countries were receiving lifelong antiretroviral therapy (ART). At the end of 2018, an estimated $79 \%$ of people living with HIV knew their status (WHO, 2019).

In Uganda, in 2018, an estimated 1.4 million people were living with HIV, and an estimated 23,000 people died of AIDS-related illnesses, During the same year, the estimated HIV prevalence among adults (aged 15 to 49 ) stood at $5.7 \%$ (UNAIDS AIDSinfo, 2019). Women are disproportionately affected, with $8.8 \%$ of adult women living with HIV compared to $4.3 \%$ of men (WHO/Uganda Ministry of Health, 2017).

However, persistent disparities remain around who is accessing treatment and many people living with HIV experience stigma and discrimination (Uganda AIDS Commission, 2015)

According to the Ugandan population-based HIV impact assessment (UPHIA) 2016-2017, the current prevalence of HIV among adults aged 15-64 years varies across Uganda, about $7.9 \%$ and $7.4 \%$ in south-western Uganda and Bushenyi respectively are both higher than the national Prevalence of $6.7 \%$.

In 2014 , only $38.5 \%$ of young Ugandan women and men aged $15-24$ could correctly identify ways of preventing the sexual transmission of HIV and rejected major misconceptions about HIV transmission (Joint United Nations program, 2017). According to Uganda AIDS Commission 2016 which stressed more about the country's 2015/20162019/2020 prevention strategy found three targets which included, increase adoption of safer sexual behaviours and reduction in risk behaviours and use of biomedical HIV prevention interventions such as voluntary medical male circumcision and PrEP, delivered as part of integrated health care services and to mitigate underlying socio-cultural, gender and other factors that drives the HIV epidemic.

In a 2015 survey conducted by HIV support organizations, in partnership with the National Forum of People Living with HIV/AIDS (NAFOPHANU), of people living with and affected by HIV in central and south-western Uganda found stigma, both internal and external, to be high. When the study began, more than half (54\%) reported experiencing some form of discrimination as a result of having HIV (AIlafrica.com, 2016). Also, Ugandan districts report frequent stock-outs of HIV testing kits and inadequate human resources to offer comprehensive testing and treatment services.

The use of testing for HIV globally is very low and this has increased the prevalence of HIV and many deaths due to HIV. HIV testing is often used as an umbrella term to refer to both testing and counseling services (Obermeyer et al., 2007).

Also, studies, Baral et al., (2013) and Hutchinson et al., (2006) have evidenced that ensuring universal and equitable access to HIV testing and counseling services remains a challenge for many subSaharan countries including South Africa (Shisana et al., 2014). It was reported that utilization of HCT services was lower among adolescents, the elderly, and men. The low uptake was associated with educational level, occupation, fear of involuntary disclosure, and access to HCT services. Furthermore, some groups at higher risk for HIV infection, including men who have sex with men, and young women are less likely to receive HCT services (Tonderai et al., 2014). Although some studies by Manuela et al., (2015) have found a correlation between the level of knowledge and good attitude towards the utilization of HIV screening services, a bigger question mark remains on the males aged between 18-30 years to why they don't utilize these services yet they are provided at no cost.

This imposes a risk of being infected with HIV since this age group has high-risk sexual behaviors. This study assessed knowledge and attitudes of males aged 18-30 years towards HIV counseling and testing in Kyeizooba community Bushenyi District

According to Obermeyer et al., (2007), Testing for HIV is the gateway to treatment, care, and prevention. Proper understanding of the complexity of the decision-making process which leads men to undergo an HIV test is still missing (Manuela, 2015). 
Currently, at Kyeizooba health center III in Bushenyi district, HIV/AIDS has an overwhelming total of 787 clients out of the total population of 2600 being served by the health facility, who are attending the ART clinic and 39 are children below 15 years and these statistics show the prevalence of HIV/AIDs in the community. A total of 113 were men and 635 were women (Kyeizooba HMIS 055b records, 2019). According to the health, facility records audited from May to September, out of 345 adults aged between 18 to 30 years old in the Kyeizooba community had tested and among them 103 (29.9\%) were males and 242 (70.1\%) were females (From Kyeizooba health center III HMIS 055b Records, 2019). This clearly shows that there are few males aged between 18 to 30 years turning up for HCT services yet these services are provided at no cost. This age group has high risky sexual behaviors which can expose them to a higher risk of HIV infection. HIV testing helps these youths to avoid risky behaviors since it involves counseling. However, there is a paucity of information about knowledge and attitude among males aged between 18-30 years towards HIV testing in the study area. Therefore, this study intended to assess the knowledge and describe attitudes towards HCT among the male youth in Kyeizooba community.

\section{METHODOLOGY}

\section{Area of study}

The study was conducted in Kyeizooba community at three active community trading centres and Kyeizooba Health Centre III, a government facility located in Kyeizooba village, Nyamiyaga Parish, Kyeizooba sub-county, Igara East in Bushenyi district about $40 \mathrm{~km}$ away from Mbarara in South Western part of Uganda. It started as a community health centre till 5th January 2011 when it was officially commissioned by H.E Yoweri K Museveni, the president of the Republic of Uganda. It serves a population of about 26000 from seven parishes of Nyamiyaga, Kitwe, Karaaro, Bwera, Kitagata, Buyanja, and Rutooma and 195 villages.

The facility offers services including general OPD services, HIV counseling and testing (HCT)

and treatment, Immunization, Laboratory services like serological tests, urinalysis, and stool

analysis, Maternity services which include antenatal care, delivery services, postnatal care, early infant diagnosis, EMTCT, and family planning and Pharmaceutical services like drug

dispensing.

The researcher conducted the study in three active trading centers are Nyamiyaga, Karaaro, and Kitwe where most of the male youth are always present participating in trading matoke, in bars, and Bodaboda.

Kyeizooba health facility serves a large population with few people attending ART clinics yet the place is known for too much involvement of risky sexual behaviors among the youth. It is well known by the local people in the region for mainly its services it offers at the site

\section{Study Design.}

The study used a descriptive cross-sectional study design and applied quantitative methods of data collection. This method was used because it was appropriate for this study since it was for a short duration and data was collected at one point in time. since the fieldworker selected venues where many people usually converge like in the health facility, trading centers, and Bodaboda stages, and administer questionnaires to the participants and answer them for 20 minutes at once.

\section{Study Population}

The study population was all males aged between 18-30 years of good sound mind irrespective of their marital status all living in the Kyeizooba community

\section{Sample size determination}

According to Kish et.al 1965, using a sample size formula by Kish Leslie for cross-sectional studies.

$$
\mathrm{N}=\mathrm{z} \alpha 2 \cdot \mathrm{p}(1-\mathrm{p}) \div
$$

$$
2
$$

where $p$ is the percentage of the number of youth who know about HCT and tested which is $29.9 \%$

1-P is the percentage of youth who do not know about HCT

is the absolute error of the estimated and the true percentage of those who know about HCT which is $5 \%$ with $95 \%$ confidence interval

$z \alpha$ is the standard normal deviation of $95 \%$ confidence interval which is 1.96

Therefore, by substituting in the formula, $\mathrm{N}=326.2$ youth aged between $18-30$ years

However, using modified Kish Leslie formula for available sample,

Sample size $=\mathrm{N}$

$(1+(\mathrm{N}-1))$ 


\section{$\mathrm{k}$}

where $k$ is the number of males who came for HCT which is 103

Therefore, after the substitution, the sample size to become;

Sample size $=77.67$

Hence the researcher considered 78 respondents

The sample size was attained within the selected site of the study regarding the researcher's limited time and resources. The subjects were got from three parishes Nyamiyaga, Karaaro, and Kitwe which has three developing trading centers that are active daily and at the health facility simultaneously

\section{Sampling procedure}

The researcher used convenient sampling because the researcher selected subjects at hand in selected sites as long as they were in the age bracket and willing to participate. It was superlative to use the whole population, but it is not possible to include every subject because the population is almost finite. This is the rationale behind why the researcher used this sampling technique

\section{Inclusion Criteria}

There was gender restriction but no racial restriction in sample selection, only males who stayed in the study site participated whether a munyankole or not.

All males aged between 18-30 years irrespective of marital status, religion, education level, occupation, and tribe were included in the sample size.

All males within the age bracket in the data collection sites, who consented to participate in the study

\section{Exclusion criterion}

There was an age restriction, so those below 18 and above 30 years were not allowed to participate.

Males who were within the considered age bracket and were not in the study area at the moment we're not waited to participate in the study

\section{Quality control}

\section{Reliability of data}

Refers to the consistency with which the research instrument measures the target attributes. Pretesting of questionnaires was done before the actual exercise of data collection. The study tool was pretested to 10 men aged 18-30 from Ruti ward and then the researcher got the clue about the questionnaire and modified it where necessary.

\section{Validity of data}

According to Polit et al., (2012), this criterion refers to the degree to which an instrument measures what it is supposed to measure. The researcher, therefore, read widely on the topic and the questionnaire was selected to collect data which was designed to contain all the information to cater to all the objectives of the study. The questionnaire was designed with the help of the research supervisor to make sure that all the necessary information was included.

\section{Pilot study}

A pilot study is a small-scale version of a planned study that allows the researcher to practice and assess the effectiveness of their planned data collection tool (Doody et al., 2015). A pilot study was conducted to test the tool if it was measuring what it intended to measure. Only 10 male youths within the age bracket in Ruti trading were selected. This site was selected because it had men who have similar economic activities like selling bananas and bodaboda riders, same culture, and also the place has men who have risky sexual behaviors as those in the actual study area. Any ambiguous questions not understood were modified. Also, the findings were not part of the main study. The researcher gained skills in data collection using a questionnaire tool before the main study.

\section{Data collection tool}

The study used a self-administered questionnaire to those who knew how to read and write English or Runyankole Rukiga and the researcher administered it to those who could not read and write to gather information from the respondents. The tool is less costly, offers anonymity, and fewer chances of interview bias (Polit et al., 2012). It was chosen because it enabled the researcher to reach out to the respondents in a short time and easy to use as its self-administered. The tool had been adopted and modified based on literature review and guided by the supervisor to fit in the study area.

The questionnaire also adopted the Brief HIV Knowledge Questionnaire scale (HIV KQ-10) that uses false/true prompts. It has mean performance ranges that show the level of knowledge from the respondents according to their mean performance (Carey et al., 2002). The mean score will be determined and graded as low knowledge if the mean score ranges between below 5 , moderate knowledge if the mean score ranges between $5-7$, and 
high knowledge if the mean score ranges between 8-10.

Furthermore, the researcher adopted a Likert scale 1932 by Bowling 1997, Burns and Grove 1997 to measure attitude directly. It was consisting of four constructs of strongly agree, agree, disagree, and strongly disagree. The rating criteria of these constructs shall depend on the statement of a particular attitude, whether it's positive or negative and favorable or unfavorable. The rating scale was having 9 statements that used strongly agree, agree, disagree, and strongly disagree scoring 1,2,3, and 4 respectively

The minimum score was 9, and the mid score was 22.5 whereas the maximum score was 36 . The score below 22.5 was regarded as a negative attitude and the score above 22.5 was a positive attitude.

\section{Data collection procedure}

During data collection, the researcher selected three research assistants who had skills in data collection and knew Runyankole Rukiga fluently. The purpose of these research assistants was to explain and give questionnaires to the participants in the three selected data collection sites on the same days, happening at the same time so that data is collected simultaneously to avoid the bias of reselection of participants who have already participated at the facility and other sites since there is a possibility of mixing again. The assistants and the researcher first discussed the questionnaire before the initiation of data collection to ensure clarity. These assistants did not participate in the data analysis, results in review, and discussion. Upon approaching the participants at hand, the researcher and research assistants would introduce themselves to the participants and explain to them the purpose of the research then requested them to sign written informed consent. The researcher and his assistants informed participants about their right to withdraw from the study and then allowed them to ask questions for clarification. The questionnaire was written in both English and Runyankole to cater to those who did not understand English. Questionnaires were availed to the participants who consented to participate in the study and were administered by the researcher and three research assistants. Unique identification numbers on the questionnaires were given to ensure confidentiality. The questionnaires were administered and collected on the same days simultaneously at both sites.

\section{Data analysis}

According to Polit et al., (2012), statistical analysis of quantitative data helps makes sense of the information rather than just a chaotic mass of numbers. Therefore, this study used Statistical Package for Social Scientists (SPSS) version 20.0, and the information obtained was represented in form of tables, graphs, and pie charts.

\section{Ethical Consideration}

Approval of the research proposal was attained and authority from the Health center in charge, district health officer, and local council leaders was sought to conduct this study. Informed consent was obtained from participants before administering the questionnaire to them and confidentiality was ensured at all times during the study. No names were used on the questionnaire but only codes and the information generated was kept under key and lock only accessible by the researcher

\section{Dissemination of results}

A copy of the final complete research will be put in the nursing department library, MUST the main library for easy accessibility and reference by other students and researchers, Kyeizooba health facility, and district health officer. Study results will be disseminated to the Department of Nursing, faculty of medicine at MUST, and kyeizooba health center III administration.

\section{Participant demographics \\ 4 RESULTS}

The targeted study sample was 78 males aged between 18-30 years from three selected parishes of the Kyeizooba sub-county and all of them participated willingly making a response rate of $100.0 \%$ $(n=78)$. There was a slight average of participation with $30.8 \%$ from Kararo, 33.3\% from and Nyamiyaga 35.9\% from Kitwe. The researchers also considered the marital status of participants with $37.2 \%$ married. $34.6 \%$ single, $12.8 \%$ had divorced and $15.4 \%$ were in a relationship. $57.7 \%$ of participants had not produced, 32\% had between 1-3 children and only $1 \%$ had four children and above.

Furthermore, the education level of the participants was considered and $11.5 \%$ of the participants were not educated, $15.4 \%$ stopped in the primary, $44.9 \%$ had completed secondary and others were 
in secondary while $28.2 \%$ were at the tertiary level and most of the participants were unemployed and liked football as their hobby. The demographic results are illustrated in the table below

\section{Knowledge performance range adopted}

Out of 10 questions of true and false responses, 28 participants scored below 5, 32 participants scored between 5-7 and 18 participants scored between 8-10 as summarized in tables below.

Low knowledge= below 5

Moderate knowledge $=5-7$

High knowledge $=8-10$

Results showed that most of the participants had moderate knowledge about HIV testing and counseling followed by low knowledge with just a different of 4 participants.

\section{Participants attitudes towards HIV testing and counselling}

\section{Attitude rating scale adopted}

Participants scored between 9-21 and 21(269 participants scored 22-36

\section{Number of times tested shown in figure one $\mathbf{0}=$ Never tested}

The researcher also asked the participants reasons for testing for those who have ever tested. $34.1 \%$ reported knowing their status, $65.9 \%$ reported that they had played sex previously with someone they did not trust.

A high percentage of $48.7 \%$ preferred a health centre, $26.9 \%$ preferred trading centre and only 24.4 preferred being tested from their homes as illustrated in the table above

Findings on going to the health facility for HIV drugs show that $55.1 \%$ of participants said that they will not be ashamed when test positive and $44.9 \%$ said that they will be ashamed. The results are illustrated in the table above

\section{DISCUSSION.}

\section{Demographic characteristics of the partici- pants.}

The analysis of participants' address showed a slight increase in the number of participants from the Kitwe trading center. This could be due to the high population of the youth from Kitwe parish and also having daily active trading Centre where these youths usually converge.

Most of the participants were married 37.2( $n=29)$ followed by a single of $n=27$. This was because of inclusion criteria of aged youth between 18-30 years where most of the youth have just married which is also an indication of children's number where most of the participants had not yet produced. There is a significant correlation between marital status and HCT uptake as evidenced by Richardson et al., (2017), a study he conducted in Uganda, and the findings showed that $29.1 \%$ of the married used HCT as compared to $21.2 \%$ of unmarried in one the study sites in Rakai.

Most of the participants were in the secondary with $44.9 \%(35)$ and others had completed the secondary level. This could be due to collecting data during the COVID 19 pandemic where all schools were closed and most of the male youth were in the community. There is a close association between education level and HCT uptake because educated youth have high knowledge about the use of HCT as a way of HIV prevention. This study is in line with that of Muyunda et al., 2018 whose findings indicated that $80 \%$ of the study participants had completed secondary education and tested for HIV and only $20 \%$ of the participants who were not educated did not know about the use of HCT.

Furthermore, most of the participants $42.3 \%(n=33)$ were unemployed. This could be due to data collection during the lockdown for COVID 19 where most of the companies were closed. There is a clear association between unemployment and HCT. Unemployment is also related to poverty which can be the cause of poor male involvement in HCT. The findings of this study agreed with Djan et al., (2018), whose findings indicated that $47 \%$ of people with low-income status due to unemployment had tested for HIV.

The researcher also considered the participant's hobbies, and it was found out that most of the participants $42.4 \%$ like football. Considering football into the youth-friendly services at health centers would attract more male youth to come to the health Centre and end up involving in HCT. Also due to peer groups among the footballers can influence others to involve in risky sexual behaviours hence the need for testing. The correlation of football as a hobby most liked by the participants and HCT is to a high extent agreeing with a qualitative study by Charles et al., (2019) in Uganda where most of the participants accepted HCT at the football site and televised football halls.

Knowledge of males aged between 18-30 years about HCT 
Table 1. articipants demographics $(n=78)$

\begin{tabular}{|c|c|c|}
\hline CHARACTERISTIC & FREQUENCY & PERCENTAGE \\
\hline $\begin{array}{l}\text { Location: Kararo, Nyamiyaga, } \\
\text { Kitwe }\end{array}$ & $24,26,28$ & $30.8,33.3,35.9$ \\
\hline $\begin{array}{l}\text { Marital status: Married, Single, } \\
\text { Divorced, In relationship }\end{array}$ & $29,27,10,12$ & $37.2,34.6,12.8,15.4$ \\
\hline $\begin{array}{l}\text { NUMBER OF CHILDREN: 0, 1-3, } \\
\text { Above } 4\end{array}$ & $45,25,08$ & $57.7,32,1$ \\
\hline $\begin{array}{l}\text { EDUCATION level: Not educated, } \\
\text { Primary, Secondary, Tertiary }\end{array}$ & $9,12,35,22$ & $11.5,15.4,44.9,28.2$ \\
\hline $\begin{array}{l}\text { OCCUPATION: Business, Em- } \\
\text { ployed, Farming, Unemployed }\end{array}$ & $19,10,16,33$ & $24.4,12.8,20.5,42.3$ \\
\hline $\begin{array}{l}\text { HOBBY: Football, Outing with } \\
\text { friends, Playing cards }\end{array}$ & $33,22,23$ & $42.4,28.2,29.4$ \\
\hline
\end{tabular}

Table 2. Participants' knowledge on HIV testing and counseling

\begin{tabular}{lll}
\hline QUESTIONS & $\begin{array}{l}\text { TRUE Frequency } \\
\text { (percent) }\end{array}$ & $\begin{array}{l}\text { FALSE } \\
\text { Frequency(percent) } \\
\text { HIV testing as a gate way to prevention of HIV and initiation } \\
\text { of treatment }\end{array}$ \\
$\begin{array}{ll}42(53.8) \\
\text { HIV transmission talk with the counselor }\end{array}$ & $63(80.7)$ \\
Testing is a time wastage & $45(57.7)$ & $15(19.3)$ \\
Knowing your status demotivates & $48(61.5)$ & $33(42.3)$ \\
HIV testing specimen as urine, stool but not blood only & $20(25.6)$ & $30(39.5)$ \\
Receiving HCT results on the same day after testing & $46(59)$ & $58(74.4)$ \\
First negative results within one of sex are reliable & $53(67.9)$ & $32(41)$ \\
No need to test again after testing first & $34(43.6)$ & $25(32.1)$ \\
Testing should be done annually irrespective of sexual & $53(67.9)$ & $44(56.4)$ \\
partners met & & $25(32.1)$ \\
Test everyone who comes at the facility & $40(51.3)$ & $38(48.7)$ \\
\hline
\end{tabular}

Table 3. Knowledge performance range adopted

\begin{tabular}{lll}
\hline PARTICIPANTS & SCORE RANGE & AVERAGE SCORE \\
28 & Below 5 & 28.9 \\
32 & $5-7$ & 57.4 \\
18 & $8-10$ & 84.2 \\
\hline
\end{tabular}

Table 4. Knowledge performance range adopted

\begin{tabular}{llll}
\hline Knowledge & Frequency & Percentage of participants & Average score \\
Low & 28 & 35.9 & 28.9 \\
Moderate & 32 & 41.0 & 57.4 \\
High & 18 & 23.1 & 84.2 \\
\hline
\end{tabular}


Table 5. participants' attitudes towards HIV testing and counseling

\begin{tabular}{|c|c|c|c|c|}
\hline STATEMENTS & SA F(\%) & A F(\%) & D F(\%) & SD F(\%) \\
\hline $\begin{array}{l}\text { HIV testing is } \\
\text { painful and causes } \\
\text { a lot of blood loss }\end{array}$ & $30(38.5)$ & $23(29.5)$ & $18(23.1)$ & $7(09)$ \\
\hline $\begin{array}{l}\text { The health facility } \\
\text { is very far from me } \\
\text { and when I go there } \\
\text { for testing there is } \\
\text { lining up which is } \\
\text { time wastage and } \\
\text { even health work- } \\
\text { ers attend to fe- } \\
\text { males first and they } \\
\text { talk to me badly }\end{array}$ & $3(3.8)$ & $16(20.5)$ & $34(43.6)$ & $25(32.1)$ \\
\hline $\begin{array}{l}\text { Getting tested for } \\
\text { HIV helps people } \\
\text { feel better }\end{array}$ & 18(23.1) & $27(34.6)$ & 28(35.9) & $5(6.4)$ \\
\hline $\begin{array}{l}\text { When people see } \\
\text { me testing, they } \\
\text { think that i played } \\
\text { sex }\end{array}$ & 31(39.7) & $29(37.2)$ & $17(21.8)$ & $1(1.3)$ \\
\hline $\begin{array}{l}\text { I do not need to } \\
\text { test when my sex- } \\
\text { ual partner tells me } \\
\text { that she is HIV neg- } \\
\text { ative and faithful }\end{array}$ & $9(11.5)$ & $38(48.7)$ & $25(32.1)$ & $6(7.7)$ \\
\hline $\begin{array}{l}\text { Getting tested for } \\
\text { HIV helps people } \\
\text { from not getting } \\
\text { HIV }\end{array}$ & $9(11.5)$ & $22(28.2)$ & $39(50)$ & $8(10.3)$ \\
\hline $\begin{array}{l}\text { People in my life } \\
\text { would leave me if } \\
\text { I had HIV and I may } \\
\text { lose my job }\end{array}$ & $35(44.9)$ & $10(12.8)$ & 28(35.9) & $5(6.4)$ \\
\hline $\begin{array}{l}\text { People who test } \\
\text { HIV positive should } \\
\text { hide it from others } \\
\text { to avoid broken } \\
\text { relationships }\end{array}$ & $08(10.3)$ & $39(50)$ & $27(34.6)$ & $4(5.1)$ \\
\hline $\begin{array}{l}\text { I would rather not } \\
\text { know if I have HIV } \\
\text { because it stresses } \\
\text { me and I don't like } \\
\text { taking every day } \\
\text { drugs for HIV }\end{array}$ & 18(23.1) & 29(37.2) & $29(37.2)$ & $2(2.6)$ \\
\hline
\end{tabular}

Table 6. Attitude rating scale adopted

\begin{tabular}{lll}
\hline Attitude & Frequency (\%) & Average score \\
Negative & $57(73.1)$ & 16.3 \\
Positive & $21(26.7)$ & 28.7 \\
\hline
\end{tabular}




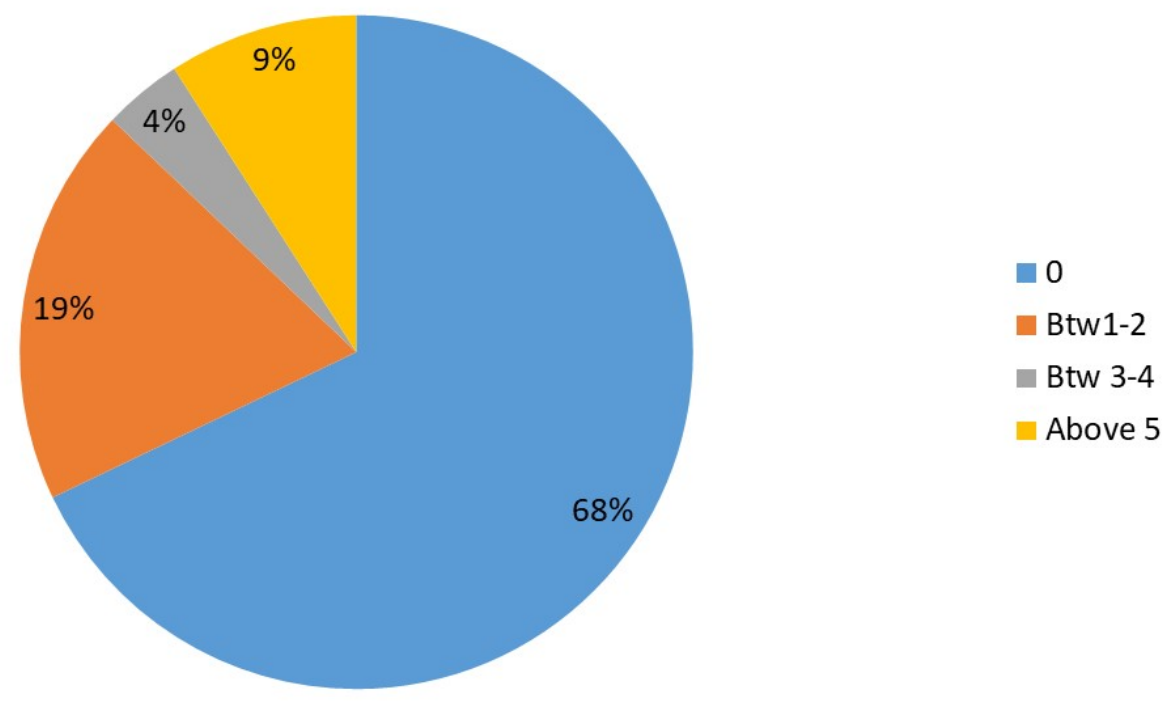

Chart 1. Number of times tested shown in figure one

Table 7. Reasons for testing

\begin{tabular}{lll}
\hline $\begin{array}{l}\text { Reasons for } \\
\text { testing }\end{array}$ & Frequency & Percent \\
Know status & 15 & 34.1 \\
Played sex & 29 & 65.9 \\
Total & 44 & 100.0 \\
\hline
\end{tabular}

\section{Table 8. Testing site preference}

\begin{tabular}{lll}
\hline SITES & Frequency & Percent \\
Health centre & 38 & 48.7 \\
Trading centre & 21 & 26.9 \\
Home & 19 & 24.4 \\
Total & 78 & 100.0 \\
\hline
\end{tabular}

\section{Table 9. Ashamed of HIV drugs}

\begin{tabular}{cll}
\hline Response & Frequency & Percent \\
NO & 43 & 55.1 \\
YES & 35 & 44.9 \\
Total & 78 & 100.0 \\
\hline
\end{tabular}


The findings of this study indicated that regarding knowledge about HCT, male youth aged between 18-30 years old had moderate knowledge about HCT. This moderate performance may be due to socioeconomic status including the education level of the participants and marital status.

According to Kirakayo et al., (2017) in their study in Burkin Faso, expanding a complete understanding of HCT of the individual requires exhaustion of the variable complexes including education level and knowledge about HIV. There is a close correlation between education level and HCT uptake because educated youths have high knowledge about the use of HCT as a way of HIV prevention. Through their training different bias, stigma, and misconception about HCT keeps on reducing at each level because of the acquisition of knowledge about HIV through interaction with peers and teachers since HIV has been introduced in the study curriculum in secondary schools. Also, moderate knowledge is highly attributed to the education level in this study since most of the participants were at the secondary level.

The first question in the knowledge section was about the main role of HCT as the gate for HIVIAIDs prevention and initiation of treatment early. Most of the participants $53.8 \%$ supported the statement. This implies that most of the participants had got some information about the use of HCT through health education to the community members. Community out-reaches are usually conducted monthly in the kyeizooba community by health workers from the health facility. There is a significant relationship between the use of HCT and its uptake since it's perceived as a benefit as illustrated in the conceptual model. However, no studies in Uganda show people's knowledge about HCT as a gateway to HIV prevention and ARVs drug initiation.

$80.7 \%$ of the participants agreed with the statement that before testing is done, the youth should talk with the counselor about HIV transmission. This implies the need for the counselor and having informed consent from the youth.

Counseling during HCT offers confidentiality, consent and the extent to which routine testing encourages prevention, reduces stigma, bias, misconception, and promotes behavior change which allows a person to test voluntarily and doing it more again after three months as the next appointment with the provider (Carla et al., 2007). The current study aligned with the study by llana et al., (2014) in Zambia who conducted a study about the use of counseling and the results showed that $87 \%$ of respondents were able to use a condom, disclose the results to the partners, reduce sexual partners and being faithful in the post counseling as compared to pre-counseling hence an indication for the need of counseling by the youth in Kyeizooba during HCT.

Furthermore, most of the participants supported the statements that HCT is a time wastage and knowing your serostatus demotivates when tested positive with a percentage of $57.7 \%$ and $61.5 \%$ respectively. This gives a clue that the participants are not interested in HCT and anxious about knowing their positive results in a case. In Uganda, no study has tried to find clients' self-driven limitations for the uptake of HCT. Also, demotivation after positive results is due to the perception of risks and consequences of HIV like rejection by loved ones, loss of job and housing, discrimination and violence (Abermeyer, 2007).

Participants were also asked if it's true or false that HIV testing specimens are urine and feces but not only blood. Most of the participants $74.4(n=58)$ responded that it is false. This implies that some participants have seen or attended HCT services while others may have heard it from their friends. However, no study in Uganda has been conducted about the specimen's knowledge of HIV testing among youth males.

Also, most of the participants $56.4 \%$ disagreed with the statement that not need to test again once you test for the first time. This implies that most of the participants do not rely on the first test results accuracy and also some may involve in sexual risky behaviours after testing for the first time which may impose them the risk of getting HIV hence the need for testing again. According to WHO of 2019 new recommendations release showed a standard HIV testing strategy which uses three consecutive reactive tests to have a maximum accuracy in HIV testing and also making appointments of returning to test again after three months once tested negative.

\section{The attitude of males aged between 18-30 years towards HCT.}

The findings of the study revealed that male youths aged between 18-30 years have a bad attitude towards HCT. Most of the participants $73.1 \%$ $(n=57)$ with a mean score of 16.3 which is even be- 
low the average of 18 according to the attitude rating scale adopted. The bad attitude among these males in the Kyeizooba community could be due to fear to be pricked, lack of sensitization about HCT, location of the health facility, long waiting hours, being judged by friends, discrimination, stigma from the community members when found positive, avoid broken relationships and divorce, stress if in case of positive results, loss of jobs and the community bad perception and considering a person as a weak, useless dead HIV/AIDs person and nicknamed as a deceased HIV person. The current findings are in line with the study conducted in Uganda by Nangendo et al., (2020) whose findings discovered that 112 participants feared to be pricked, 162 feared testing related gossip, $9.9 \%$ stressed long waiting at the facility during testing, and $8.1 \%$ agreed with the facility being far from them and other suggested more sensitization about HCT benefits by health workers. Furthermore, it was also discovered that fear, stigma, and low-risk perception remain barriers for HIV testing among young men for example fearing to lose friends after being recognized as an HIV patient Jonas et al., (2019), therefore this study is agreeing with the current study.

On the more statements about the attitude towards HCT, most of the participants 34/43.6\% disagreed with health facility being far from them to access HCT services. This could be because the health facility is strategically located in the study sites selected, which are very close to the facility. Facility distance and HCT service uptake are related. This is because long distances take a lot of time to reach the facility and miss services when finding the facility already closed. No evident studies in Uganda that clearly shows the impact of facility distance on HCT utilization.

$35 / 44.9 \%$ of the participants strongly agreed with the statement that they would lose jobs and friends when tested positive. This implies that most of the participants could not disclose their results to friends, partners, and co-workers because they fear losing them and this results in spreading of infection to their fellow friends since they would not know their status. This study is aligned with the study by martin et al., 2016 in south Africa, whose findings revealed that most of the participants feared being stigmatized, broken confidentiality and discrimination at work place and may lose their jobs. This is an indication of the stigma among the worker.

The participants drew on the stress after testing if found positive, $37.2 \%$ agreed and others disagreed. This implies that stress after testing still exists among the youths irrespective of interventions made by the health facility. The current results of the study are proportionally agreeing with the study by Kagee et al., (2017) in south Africa whose findings showed most of the participants signified fear, stress, depression and anxiety upon receiving their results.

$48.7 \%, n=38$ of the participants agreed with the statement that they do not need to test when their sexual partner tell that she is faithful. This is could be an indication of why they do not test because of false assurance from their partner and few turning up for HCT without their partners. The current findings are agreeing with qualitative study done by Victoria et al., (2017) in Uganda where most of the respondents stressed that testing is related to trust among couples and therefore if one partner is faithful, no need to test and also if found testing the partner may think that you have been going out to other sex workers.

Furthermore, 39/50\% of the participants agreed with the statement that to avoid broken relationships and divorce, positive results should not be disclosed to their partners. This could be the reason why participants are not testing with their partners to avoid disappointments, the current study is in agreement with the one conduct in Ethiopia by Erena et al., (2019) where 49.7 believed to have lost respect from partners and $30 \%$ hesitated to take HIV test because of reactions of other people especially their spouses if positive.

Also, of all the participants $68 \%$ of the participants had never tested and to those who had tested, the most $65.9 \%$ had played sex with somebody they did not trust as the sole reason for testing, and 34.1 wanted to know their status. This further indicates that these youths aged between 18-30 years old are not involving in HCT yet its provided at no cost. Also, these male youths are very active and involve in risky sexual behaviours which impose them at risk of getting HIV. The current study is aligned with one conducted by Peltser et al., (2013) in south Africa whose findings shows that only $25.8 \%$ of the youths had tested, $47.8 \%$ had never tested and $26.4 \%$ had tested more than 
once and for most of the participants 73.9\%, their recent HIV test was less than a year ago.

Most of the participants $47.8 \%$ preferred a health facility as a testing site and $50.1 \%$ said they won't be ashamed of taking drugs when tested positive. Health facility preference as a testing site implies may be the need for confidentiality, comfort, and privacy. The current study findings of testing site preference are highly supported by the study conducted by Ucheoma et al., (2019) in Nigeria whose findings revealed that most of participants $50.6 \%$ preferred health facilities followed by home testing then mobile testing or trading centers. Furthermore, most of the participants stressed that they will not be ashamed of taking HIV drugs when test positive. This could be due to the knowledge got in their schools about the use of taking HIV drugs to reduce viral multiplication and hence reducing viral load. No study in Uganda clearly states the reasons why young youth are ashamed of taking ARVs though it may be related to stigma and stress.

\section{Conclusion}

Generally, the participation of male youths aged between 18-30 years in HCT was very low in Kyeizooba. This was found to be highly linked with a bad attitude towards HCT including barriers like stigma, discrimination when tested positive, long waiting hours at the facility, loss of jobs and friends, and divorce or relationship breakups which the participants agreed with such statements. Therefore, concerted efforts at the Kyeizooba health facility is needed to break all these beliefs and misconceptions related to HCT. The participants have moderated knowledge about HCT though they are not incorporating knowledge in HCT.

\section{Implications}

The research findings could help nurse practitioners to know the myths and misconceptions about HIV/AIDs, HCT among the youths and be able to address them satisfactorily

The findings could contribute to the efficient use of teaching methods and aids by the nurse educators when giving health education talks and when counseling the clients

The research findings could help policymakers and realize the packaging of education programs especially sex education and inclusion of youth friendly services at all health facilities.
Research findings could be used for further studies about attitudes among youth towards HCT in other regions of the country.

From the above implications, the overall outcome would be an increased number of young people testing, knowing their serostatus, have future behaviour changes and in turn reduction in new HIV infections and initiation of treatment early.

\section{Recommendations.}

Based on the findings in the study, the researcher wishes to make the following recommendations.

Policymakers need to package health education sessions at all levels of youth centers in Uganda about HCT.

The facility administration should come up with a protocol that harnesses testing of all youths who come for other routine out-patient care services.

The public health programs especially for the youth should install youth-friendly services in the youth-friendly corner within all health facilities of Uganda

\section{Further research}

Further research is recommended to find out motivational related factors that can lead to HCT uptake among the male youths

\section{Limitations}

The research was conducted in only three parishes out of seven parishes that were around the health facility and therefore imposes a limitation on generalization in the whole sub-county, district, and Uganda at large. This should be considered in the future for more generalization

Participants, who could not read and write either English or Runyankole, did not give information as expected. Therefore, the researcher could try to direct them in answering the tiresome questions.

Covid 19 pandemic was also a limitation as participants would first get scared and others could even run away.

\section{Acknowledgment}

I would like to acknowledge the following for their contributions to the success of my research project.

First of all, I thank the Almighty God for His love and protection during my stay at MUST.

I send my dear gratitude towards my parents Mr. \& Mrs. ENSERIKUBI ERIKANAH and JAIRENCE, my sister, and my brothers for their spiritual, financial, 
emotional, and social support and their unconditional love.

Thanks to my dear supervisor Mr. NIYINZIMA VALENCE for all the assistance right from developing the proposal to the dissertation.

\section{List of Abbreviations and}

\section{Acronyms}

ART Antiretroviral Therapy

HBM Health Belief Model

HCS HIV testing and counseling services

HCT HIV Testing and Counseling

OPD Out-patient Department

PMTCT Prevention of Mother to Child Transmission

PrEP Pre-exposure Prophylaxis

UDHS Uganda Demographic Health Survey

UNAIDS The Joint United Nations Programme on HIV/AIDS

\section{Definition of Terms}

Attitude: The feelings, beliefs, and behavior predispositions directed towards HIV testing and counseling

HIV Testing and Counseling: This involves risk assessment, risk reduction, emotional support and referral and is done using an approved HIV testing protocol

Key Population: The people who inject drugs, men who have sex with men transgender persons, sex workers, and prisoners.

Knowledge: The condition of knowing HIV testing and counseling in association with others

Stigma: The disapproval of or discrimination against a person based on perceivable social characteristics that serve to distinguish them from other members of a society.

\section{A References:}

1) Allafrica.com (2016) "Uganda: Stigma Against HIV/Aids Patients High". [Online] Available at https ://allafrica.com 201605231253 [accessed on 30th September 2019.

2) Baral, SD., Ketende, S., Mnisi, Z.,\& Mabuza ,X, Grosso, A, (2013) "A crosssectional assessment of the burden of HIV and associated individual- and structural-level characteristics among men who have sex with men in Swaziland". J Int AIDS Soc 16 Suppl, 3, page187. https://doi.org/10.7448/IAS.1 6.4.18768 PMid:24321117 PMCid:PMC3852353
3) Bowling, A (1997) Research models. Buckingham. Open University press

4) Carey, M.P., \& Schroder, K.E (2002) "Development and psychometric evaluation of the brief HIV Knowledge Questionnaire".AIDS Educ. Prev 14, 172182. https://doi.org/10.1521/aeap.14.2.172.23902 PMid:12000234

5) Carla M,O., \& Michelle O. (2007) The utilization of testing and counseling for HIV: A review of the social and behavioral evidence. American journal of public health 97(10) page $1767 \mathrm{https}: / /$ doi.or g/10.2105/AJPH.2006.096263 PMid:17761565 PMCid:PMC1994175

6) Carla, M, Obermeyer, D, \& Michelle, O (2007) "The Utilization of Testing and Counseling for HIV".A Review of the Social and Behavioral Evidence.American Journal of Public Health, 97. https://doi.org/10.2105/AJPH.2006.096263 PMid:17761565 PMCid:PMC1994175

7) Charles P., Godfrey S., \& kiwanuka N (2019) Acceptability of HIV testing for men attending televised football venues in Uganda; BMC public health 19, article number 1136 https://doi.or g/10.1186/s12889-019-7478-6 PMid:31426776 PMCid:PMC6700992

8) Djan D (2018) Factors affecting the attitude of young people towards HCT in rural Ghana. Journal of hiv retrovirus 4 https://doi.org/10.21767/2471-9 676.100045

9) Doody J., Rhind D., Green B., \& Castellano C (2015) Chronic effects of an invasive species on an nimal community ecology 98(8) https://doi.org/10. 1002/ecy.1889 PMid:28477376

10) Erena N., \& Shen G (2019) Factors affecting HCT among Ethiopia women aged 15-49, 1076(2019)

11) Health Protection Surveillance Centre (HPSC), HIV and AIDS (2011) "Some Facts". [Online] Available athttps://www.hpsc.ie/a-z/hivandaids [Accessed on 07/09/2019].

12) Hutchinson, PL., \& Mahlalela, $X(2006)$ "Utilization of voluntary counseling and testing services in the Eastern Cape, South Africa". AIDS Care, 18, page 446-455. https://doi.org/10.1080/095401205 00213511 PMid:16777636

13) Ilana L., \& Wang W. (2014) Unravelling the quality of HIV counseling and testing services in the private and public sector. Health policy and planning Zambia 29(1) https://doi.org/10.1093/hea pol/czt036 PMid:25012796 PMCid:PMC4095920 
14) Kagee A., Saal W., \& Bantjes J (2017). Distess, depression and anxiety among presons seeking HCT, AIBS care 29(3). https://doi.org/10.10 80/09540121.2016.1259453 PMid:27866410 PMCid:PMC5839623

15) Kirakayo S., \& Mathieu S (2017). Uptake of HIV testing in Burkina Faso: an assessment of individual and community level determinant; BMC public health 17(1) https://doi.org/10.1186/s12889017-4417-2 PMid:28532440 PMCid:PMC5441086

16) Kish L (1965) Survey sampling. New york:John wiley and sons

17) Likert, $R$ (1932) A technique for the measurement of attitudes. Archives of psychology, 140, 1-55

18) Manuela, D., Isabelle, A., Justin., Valerie, $R$, Maurice, Y, Olaf, M., \& Malabika, S (2015) "Factors Affecting the Uptake of HIV Testing among Men".A Mixed-Methods Study in Rural Burkina Faso. Uptake of HIV Testing among Men in Rural Burkina Faso page 7-12.

19) Muyunda, B., Musonda P., \& Michelo C. (2018) Educational attainment as a predictorof HCT uptake. Department of epidemiology and biostatistics, Zambia 196(6) page 7

20) Nangendo J., Katahoire A R., Mari A,Kabami J., Odei O G., \& Muwema M (2020) Prevalence, associated factors and perspectives of HIV testing among men in Uganda https://doi.org/10.1371/journal.po ne.0237402 PMid:32764820 PMCid:PMC7413494

21) Obermeyer M.C., \& Osborn M., (2007) The Utilization of Testing and Counseling for HIV: A Review of the Social and Behavioral Evidence. American Journal of Public Health (ajph). https://aj ph.aphapublications.org/doi/ref/10.2105/AJPH.20 06.096263 https://doi.org/10.2105/AJPH.2006.096 263 PMid:17761565 PMCid:PMC1994175

22) Peltzer K., \& Maskete G (2013) Determinants of HIV testing among young people aged 18-24 years in south Africa, Africa health sciences 13(4) ht tps://doi.org/10.4314/ahs.v13i4.22 PMid:24940326 PMCid:PMC4056506

23) Polit D., \& Beck C (2012)Nursing research:Generation of evidence practice 9th edition limpicott, Williams and Wilkins, Philadelphia

24) Richardson M., Matovu J., \& Wanyenze R (2017) HIV prevalence and uptake of HIV/AIDs services among youth; BMC public health 17 article number 251

25) Shisana O., Rehle T., Simabyi L., Zuma K., \& Jooste S. (2014) "South African National HIV Prevalence". Incidence and Behavior Sur- vey ,2012. Cape Town. [Online] Available at http://www.hsrc.ac.za/en/research-areas/Rese arch_Areas_HAST/HAST_National_HIV_Survey [Accessed on 12th 0ct 2019].

26) Tonderai M., Mary H., Bulelani K., Gavin J., Salome C., \& Christopher J H (2014) Four models of HCT: Utilisation and test results in south africa 9(7)

27) UAC (2015) "2014 Uganda HIV and AIDS Country Progress Report" [pdf]. [Online] Available at https://www.unaids.org page 35-45 [accessed on 5thoctobar 2019].

28) UAC (2015) "An AIDS Free Uganda, My Responsibility: Documents for the National HIV and AIDS Response, 2015/2016 - 2019/2020" [pdf]. [Online] Available at http://www.medbox.org [Accessed 4th October 2019].

29) Ucheoma N., Iwelunmor J., Tucker J .(2019) Preferences for HIV testing services among youth in Nigeria ;BMC health services report

30) Uganda AIDS Commission (2016) "The Uganda HIV and AIDS Country Progress Report July 2015-June 2016" [pdf]. [Online] Available at http s://www.unaids.org page 40-50 [accessed on 5th October 2019].

31) Uganda AIDS Commission (2016) "The Uganda HIV and AIDS Country Progress Report July 2015-June 2016" [pdf]. [Online] Available at http s://www.unaids.org page 40-50 [accessed on 5th October 2019].

32) Uganda Population-Based HIV Impact Assessment (2017) "Uganda population-based HIV impact assessment" act sheet. [Online] Available at https:/ /www.afro.who.int [accessed on 12th

33) Uganda Population-Based HIV Impact Assessment (2017) "Uganda population-based HIV impact assessment" act sheet. [Online] Available at https:/ /www.afro.who.int [accessed on 12th

34) UNAIDS (2017) "Addressing a blind spot in the response to HIV - Reaching out to men and boys [pdf]". [Online] Available at https://www.unaids.or $\mathrm{g}$ [Accessed on 30th October 2019].

35) UNAIDS (2017) "UNAIDS DATA 2017" [pdf]. [Online] Available at www.unaids.org [accessed 4th October 2019].

36) Victoria N., \& Eric W Jacqueline G (2017) Motivators of couple HCT uptake in rural settings in Uganda,bmc public health 17(104)

37) Victoria N., wobudeya E., \& Gahagan J (2017) Motivator for couple HIV testing uptake in rural area Uganda; BMC public health 17(104) 
38) WHO, (2019) Innovative WHO HIV testing recommendations. Available at www.who.int. [accessed on 28th November 2020].

39) WHO/Uganda Ministry of Health (2017) "The Uganda Population-Based HIV Impact Assessment 2016-17" [pdf]. [Online] Available at http://phia.ica p.columbia.edu [Accessed 14th 09 2019].

40) World health organization (2019).[Online] available at https://www.who.int/news-room/fact-s heets/detail/hiv-aids [Accessed on 14/09/2019].

41) World health organization (2019).[Online] available at https://www.who.int/news-room/fact-s heets/detail/hiv-aids [Accessed on 14/09/2019]. 